\title{
THE TONKIN SNUB-NOSED MONKEY Rhinopithecus avunculus POPULATION IN THE QUAN BA FOREST, NORTH-EAST VIETNAM: AN IDENTIFICATION OF PRIORITY HABITAT FOR CONSERVATION
}

\author{
Nguyen Xuan Dang ${ }^{1, *}$, Nguyen Xuan Nghia ${ }^{1}$, Pham Van The ${ }^{2}$ \\ ${ }^{1}$ Institute of Ecology and Biological Resources, VAST, Vietnam \\ ${ }^{2}$ Centre of Scientific Research and Practice, Binh Duong, Vietnam
}

Received 3 May 2019, accepted 4 July 2019

\begin{abstract}
The Tonkin Snub-nosed Monkey Rhinopithecus avunculus is among the World's 25 most endangered primates. At present, the species is found only in few forest areas in Ha Giang and Tuyen Quang Provinces, north-east Vietnam with a total number not exceeding 250 individuals. The forest block in Cao Ma Po, Ta Van and Tung Vai Communes of Quan Ba District, Ha Giang Province (the Cao - Ta - Tung forest) harbors the second largest population of Tonkin Snub-nosed Monkey. This population was estimated to be conisted of about 30-35 individuals in 2007. However, it faces a number of serious threats (wildlife hunting, habitat degradation by widespread forest farming of Tsao-ko cardamom plant, etc.) that may lead the population to be extinct in near future. The population was reduced to 15-21 individuals in 2016 due to these threats. In 20172018, we conducted a study to identify a priority habitat area to establish the Quan Ba Tonkin Snub-nosed Monkey Conservation Area. The results of our study show that the distribution of the Quan Ba Tonkin Snub-nosed Monkey population is confined to a small area (about 5,000 ha) belonging to the Theng Chu Phin, Dao Dan Chai, Ta Lay mountains, the Hill 754 and a forest patch along the Vietnam-China border from the Post 283 to Post 295. This area harbors the best forest of the Cao - Ta - Tung area. The forest covers $92.3 \%$ of the area, and only $7.7 \%$ of the area is a non-forest land. There are two types of forest: evergreen broad-leaved forest (50.0\% of total area) and limestone evergreen broad-leaved forest (42.3\%). The evergreen broad-leaved forest has been degraded to medium and restoration status. Tsao-ko cardamom Amomum tsao-ko fields are widespread. The limestone evergreen broad-leaved forest of almost primary status remains in very steep slopes and limestone mountains. The Cao - Ta - Tung forest was designated as a watershed protection forest that allows farming of agricultural and medicinal plants inside the forest and the forest farming of Tsao-ko cardamom is widespread becoming the most serious threat to the long-term survival of the Tonkin Snub-nosed Monkey population. In order to ensure long-term survival of the Quan Ba Tonkin Snub-nosed Monkey population, the area of the Theng Chu Pin, Dao Dai Chai, Ta Lay, Tung Lau mountains, the Hill 754 and a forest patch along the Vietnam-China border from the Post 283 to Post 285 must be designated as a specialuse forest, i.e. to establish a Quan Ba Tonkin Snub-nosed Monkey Conservation Area.
\end{abstract}

Keywords: Rhinopithecus avunculus, critically endangered primate, wildlife, conservation.

Citation: Nguyen Xuan Dang, Nguyen Xuan Nghia, Pham Van The, 2019. The tonkin snub-nosed monkey Rhinopithecus avunculus population in the Quan Ba forest, north-east Vietnam: an identification of priority habitat for conservation. Academia Journal of Biology, 41(3): 47-54. https://doi.org/10.15625/2615-9023/v41n3.13799.

*Corresponding author email: dangiebr@gmail.com

C2019 Vietnam Academy of Science and Technology (VAST) 


\section{INTRODUCTION}

The Tonkin Snub-nosed Monkey Rhinopithecus avunculus is listed in the World's 25 most endangered primates (Schwitzer et al. 2015). This species is listed as "Critically endangered" (CR) in both the Red Data Book of Vietnam (MOST and VAST 2007) and the IUCN Red List (IUCN 2019). Historical distribution range of the species covers five provinces of north-east Vietnam including Yen Bai, Ha Giang, Tuyen Quang, Thai Nguyen and Bac Kan Provinces (Pham Nhat 2002). However, at present, the species is found only in a few forest areas in Ha Giang and Tuyen Quang Provinces with a total number not exceeding 250 individuals (Covert et al. 2008, Schwitzer et al. 2015). The largest population of this species is found in the Khau Ca Tonkin Snub-nosed Monkey Conservation Area in Vi Xuyen District, Ha Giang Province. This population was first found in 2002 (Le Khac Quyet 2004), in the buffer zone of the Du Gia Nature Reserve and, to conserve this population, the Khau $\mathrm{Ca}$ Tonkin Snub-nosed Monkey Conservation Area was established in 2009. Then the population has been protected well and increased its number from about 40 individuals in 2002 to about 120 individuals in 2017 (Nguyen Van Truong et al. 2017, unpublished report). The second largest Tonkin Snub-nosed Monkey population of about 3035 individuals was found in 2007 (Le Khac Quyet \& Covert, 2010) in a forest block covering Cao Ma Po, Ta Van and Tung Vai Communes of Quan Ba District, Ha Giang Province (the Cao - Ta - Tung forest). This population is extremely vulnerably due to extensive wildlife hunting and rapid forest degradation. Since its first discovery in 2007, the Fauna \& Flora International - Vietnam Programme (FFI - Vietnam) and other nongovernmental organizations (NGOs) have supported the Quan Ba Forest Protection Department to protect this population with various measures such as intensifying forest patrol, population monitoring and public conservation awareness education. Three Commune conservation teams of 10 local villagers were established in Cao Ma Po, Ta Van and Tung Vai Communes. The teams conducted regular forest patrol for preventing Tonkin Snub-nosed Monkey hunting, forest destruction and taking records of the presence of Tonkin Snub-nosed Monkey groups. In spite of such efforts, the Tonkin Snub-nosed Monkey population has been declining. Surveys in November 2016 find only four groups with a total of 15-21 individuals (Nguyen Van Truong et al. 2016, unpublished report). Thus the situation of the Quan Ba Tonkin Snub-nosed Monkey population in this area is critical and stronger conservation measures should be undertaken immediately or otherwise, the population will be extinct soon. One of these measures is to establish and intensively manage the Quan Ba Tonkin Snub-nosed Monkey Conservation Area. Toward this purpose, we conducted a study to identify a priority habitat area in 2017-2018 and the results are reported herein.

\section{MATERIALS AND METHODS}

We reviewed all field survey reports and related literature for records of the Tonkin Snub-nosed Monkey and threat assessment. The literature reviewed includes published articles (see Reference) and the following unpublished reports: Le Khac Quyet (2007): Result of mammal survey in two communes: Tung Vai (Quan Ba District) and Ngoc Linh (Vi Xuyen District), Ha Giang Province, FFI Vietnam, Hanoi, Vietnam. Le Khac Quyet, Vu Ngoc Thanh and Luu Tuong Bach (2008): Survey of Tonkin Snub-nosed Monkey Rhinopithecus avunculus in Quan Ba District, Ha Giang Province, north-eastern Vietnam, FFI - Vietnam, Hanoi, Vietnam. Le Trong Dat (2010): Preliminary result of 2010 survey for Tonkin Snub-nosed Monkey Rhinopithicus avunculus in the Tung Vai - Ta Van - Cao Ma Po forest, Quan Ba District, Ha Giang Province, FFI - Vietnam, Hanoi, Vietnam. Thach Mai Hoang (2011): Primate Survey Prioritising Tonkin Snub-Nosed Monkey Rhinopithecus avunculus and Francois' Langur Trachipythecus francoisi in the $\mathrm{Na}$ Hang Nature Reserve, Tuyen Quang Province, Technical Report, the People Resources and 
Conservation Foundation, Hanoi, Vietnam. Nguyen Van Truong (2014): A report on population census of Tonkin Snub-nosed Monkeys in Tung Vai - Ta Van - Cao Ma Po forest, Quan Ba District, Ha Giang Province, Technical report, FFI - Vietnam, Hanoi, Vietnam. Dang Thanh Liem, Nguyen Huu Dzung, Nguyen Duc Tho and Nguyen Van Truong (2015): Results of community consultancy on proposed strategies of interventions on conservation of Tonkin Snub-nosed Monkey and Mechilia in the Tung Vai - Ta Van - Cao Ma Po forest, Quan Ba District, Ha Giang Province, Technical report, FFI - Vietnam, Hanoi. Trinh Dinh Hoang, Nguyen Huu Dzung and Pham Cong Linh (2015): An assessment of impact of forest farming of Tsao-ko cardamom Amomum tsao$k o$ and Ling xiang cao Lysimachia foenumgraecum on conservation of Tonkin Snubnosed Monkey and habitat in Quan Ba District, Ha Giang Province, Technical report, FFI -Vietnam, Hanoi. Nguyen Van Truong, Pham Cong Linh, Le Trong Dat (2016): Preliminary report of survey on Tonkin Snubnosed Monkeys Rhinopithecus avunculus in the Tung Vai - Ta Van - Cao Ma Po forest, Quan Ba District, Ha Giang Province, Technical report, FFI - Vietnam, Hanoi. Nguyen Van Truong, Pham Cong Linh (2017): Report of survey on the population of Tonkin Snub-nosed Monkey at Khau Ca Species and Habitat Conservation Area, $\mathrm{Ha}$ Giang Province, A technical Report, FFI Vietnam, Hanoi.

We interviewed local stakeholders on effectiveness of the management measures applied so far and the lesson learned from these activities. The following local stakeholders were interviewed: the Nature Conservation Unit of the Forest Protection Department of $\mathrm{Ha}$ Giang Province, the Forest Protection Department of Quan Ba District, Commune and Village leaders of Cao Ma Po, Tung Vai and Ta Van Communes and the members of the three Commune conservation teams.

We conducted transect surveys in the Cao - Ta -Tung forest to update information/ data on the distribution range of the Tonkin Snub- nosed Monkey population, forest status, status of Tsao-ko cardamom Amomum tsao-ko cultivation and direct threats to the Tonkin Snub-nosed Monkey population. Total area surveyed was about 5,000 ha and 17 line transects with a total of $30.7 \mathrm{~km}$ long were surveyed. Those transects were randomly arranged within all forest types and separated from each other by at least $500 \mathrm{~m}$. When Tonkin Snub-nosed Monkeys were spotted the following data were recorded: GPS coordinates, the number of animals observed, the number of adult males and females and of immature animals, location in canopy and the activity of the animals such as feeding, resting or locomotion.

All members of the Commune conservation teams were trained on techniques to monitor the Tonkin Snub-nosed Monkey so that they can collect observation data of the objects during their regular forest patrolling.

Based on the literature review and analysis of our field data we assessed the vulnerability of the Quan Ba Tonkin Snubnosed Monkey population and identified the priority habitat for its conservation, i.e. to establish a Quan Ba Tonkin Snub-nosed Monkey Conservation Area.

\section{RESULTS AND DISCUSSION}

\section{Status and distribution of the Quan Ba Tonkin Snub-nosed Monkey population}

The Quan Ba Tonkin Snub-nosed Monkey population was first discovered in 2007 by a FFI survey team (Le Khac Quyet \& Covert, 2010) and a number of field surveys were conducted latter by FFI Vietnam to assess the population size and identify the direct threats to the population (see un-published reports by Le Khac Quyet et al. 2008, Le Khac Quyet et al. 2010, Le Trong Dat et al. 2010; Mahood and Nguyen Huu Dzung 2011, and Nguyen Van Truong 2014). The results of these previous studies indicated that the Quan Ba Tonkin Snubnosed Monkey population was consisted of three or four groups with a total of about 3235 individuals. This is the second largest population of Tonkin Snub-nosed Monkey in 
Vietnam. However, the population has been facing with strong pressure of wildlife hunting and habitat disturbance by local residents which will lead to the extinction of this population very near future. Surveys in 2016 found four groups with a total of only 15-21 individuals (Nguyen Van Truong et al. 2016, un-published report).

All the records of Tonkin Snub-nosed Monkey groups in these previous surveys and also observations by the three Commune conservation teams during 2008 to 2018 found that the monkeys have been living in a small confined area (about 5,000 ha) of relatively intact limestone forest area belonging to the Theng Chu Phin, Dao Dan Chai, Ta Lay mountains, the Hill 754 and a forest patch along the Vietnam-China border from the post 283 to post 295 (Fig. 1).

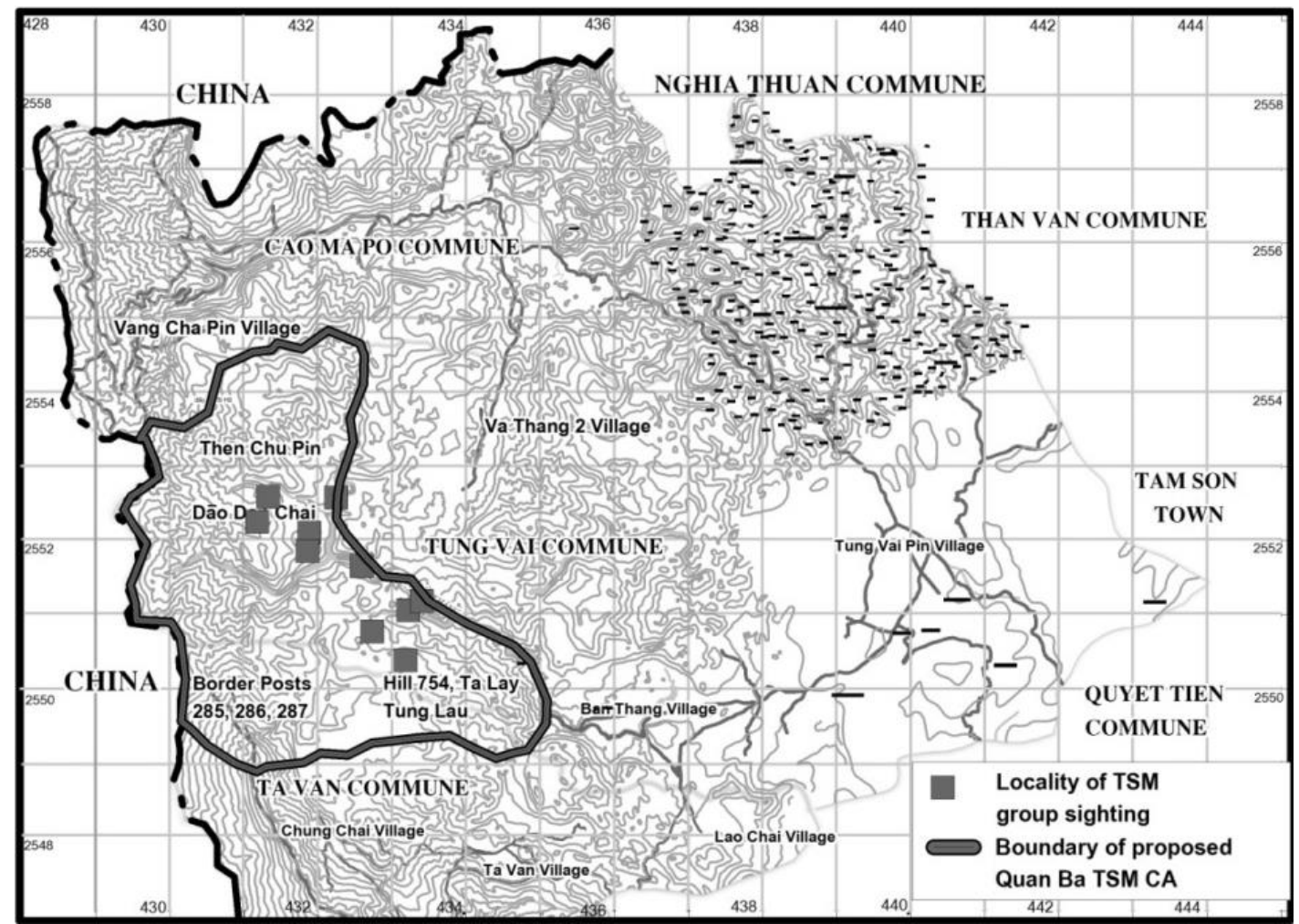

Figure 1. Distribution of the Quan Ba Tonkin Snub-nosed Monkey population and a proposed Quan Ba Tonkin Snub-nosed Monkey Conservation Area

Forest habitat of the Quan Ba Tonkin Snub-nosed Monkey population in the distribution area

In April 2018, we assessed the forest status of the distribution area of the Quan $\mathrm{Ba}$ Tonkin Snub-nosed Monkey population. The results of this study show that $92.3 \%$ of the area is covered by forests and the remaining $7.7 \%$ is a non-forest land. This area includes two types of forest: an evergreen broad-leaved forest (accounting for $50.0 \%$ of the total area) and limestone evergreen broad-leaved forest $(42.4 \%)$. No primary forest remains in the area because the forest have been strongly affected by activities such as selected timber logging and pruning trees for forest farming of Tsao-ko cardamom Amomum tsao-ko and Ling xiang cao Lysimachia foenum-graecum. These activities significantly reduced the volume of the native forests and the forests remain only at medium and restoration status 
The tonkin snub-nosed monkey

according to the forest status classification in the Circular No. 34/2009/TT-BNNPTNT of the Ministry of Agriculture and Rural Development (table 1).

Table 1. Types and status of forest in the distribution area of the Quan Ba Tonkin

Snub-nosed Monkey population

\begin{tabular}{|l|c|c|}
\hline \multicolumn{1}{|c|}{ Forest type and status } & Area (ha) & Percentage (\%) \\
\hline 1. Evergreen Broad-leaved forest (Non-limestone) & $\mathbf{2 2 8 0 . 3 5}$ & $\mathbf{5 0 . 0}$ \\
\hline - Rich forest & 49.70 & 1.1 \\
\hline - Medium forest & 1619.99 & 35.5 \\
\hline - Poor forest & 360.03 & 7.9 \\
\hline - Restoration forest & 250.63 & 5.5 \\
\hline 2. Limestone Evergreen Broad-leaved Forest & $\mathbf{1 9 3 2 . 8 1}$ & $\mathbf{4 2 . 4}$ \\
\hline - Rich forest & 173.42 & 3.8 \\
\hline - Medium forest & 746.67 & 16.4 \\
\hline - Poor forest & 151.98 & 3.3 \\
\hline - Restoration forest & 860.74 & 18.86 \\
\hline
\end{tabular}

Tsao-ko cardamom fields are widespread in the evergreen broad-leaved forests. In the fields, many tall trees have been removed resulting in the reduction of the canopy coverage to only $40 \%-60 \%$ or lower. Consequently, the remaining tree layer consists of only scattered trees of 10-20 m in hight with the DBH (diameter at breast height) of $10-20 \mathrm{~cm}$, rarely $25-30 \mathrm{~cm}$. The forest canopy is disrupted throughout this area and is not able to support the normal arboreal movement of the Tonkin Snub-nosed Monkeys. The scrub and ground layer have been completely cleared for growing Tsao-ko cardamom so that all tree seedlings were eliminated and lost regeneration capacity of the forests. Rich forest remains only in very steep slopes and limestone mountains such as the Hill 754, and the Theng Chu Phin and Dao Dan Chai limestone mountains where are not suitable to grow Tsao-ko cardamom. The forest structure in this area remains similar to the primary forest with three tree layers and the forest canopy coverage of more than $70 \%$. The trees have DBH diameter of $40-60 \mathrm{~cm}$, and a height of $20-50 \mathrm{~m}$. The dominant tree species include Castanopsis cerebrina, Castanopsis tesselata, Castanopsis tonkinensis, Quercus platycalyx, Syzygium cuminii, Cephalotaxus mannii, Magnolia grandis, Magnolia coriacea, Acer oblongum, Alniphyllume berhardtii, Rhodoleia championii, Toona sureni, Artocarpus petelotii and Garcinia oblongifolia. This forest provides a good substrate for arboreal movement of Tonkin Snub-nosed Monkeys, and the most of the Tonkin Snub-nosed Monkey groups were found in this forest type.

\section{Threats to Quan Ba Tonkin Snub-nosed Monkey population}

The result of previous studies (Trinh Dinh Hoang 2015, Nguyen Van Truong 2016, unpublished reports) and our present study show that the Quan Ba Tonkin Snub-nosed Monkey population in the Cao - Ta - Tung forest are seriously threatened by; 1) widespread forest farming of Tsao-ko cardamom, 2) selected cutting of valuable timber trees, 3) hunting wildlife with guns and 4) harvesting orchids and non-timber forest products. The most serious threats to the Tonkin Snub-nosed Monkeys appear to be the widespread forest farming of Tsao-ko cardamom and selected cutting of valuable timber trees.

The hunting wildlife with guns is the third most serious threat to the Quan Ba Tonkin Snub-nosed Monkey population. Actually, the most recent case of Tonkin Snub-nosed 
Monkey hunting was recorded in 2010 (Le Trong Dat et al. 2011, un-published report) and no further cases of hunting of the species have been recorded in recent years. However, this does not mean hunting is no longer a threat to the Tonkin Snub-nosed Monkey, because local people continue to bring guns into the forest and gun shots are still heard in the forest by the survey teams and the Commune conservation teams during their forest patrolling (Nguyen Van Truong 2016, un-published report). Selective cutting of valuable timber trees occurs commonly in the area. Local residents from Cao Ma Po, Tung Vai and Ta Van communes often encroach on the Tonkin Snub-nosed Monkey area to cut valuable timber trees for house building and other purposes. Many logging sites were found in the forest by Commune conservation teams and our survey team. Selective cutting of valuable timber trees leads to forest degradation that reduces the food sources and the locomotion substrate for the Tonkin Snubnosed Monkey population.

The most serious threat to Quan Ba Tonkin Snub-nosed Monkey population is widespread forest farming of Tsao-ko cardamom. Cultivation of agricultural and medicinal plant inside the watershed protection forest is legal. Tsao-ko cardamom fields are found in valleys, along streams and from the foot to the top of all mountains. Almost all sites that are more or less suitable for Tsao-ko cardamon have been covered by these fields. Only the limestone forests in Theng Chu Phin, Dao Dan Chai, and the Hill 754 have a few Tsao-ko cardamom fields due to their steep slopes un-suitable for Tsao-ko cardamom cultivation. Statistical data of Quan Ba District show that Cao Ma Po, Tung Vai and Ta Van Communes have the largest area of Tsao-ko cardamom fields, which accounts for $60 \%$ of the total Tsao-ko cardamom area in Quan Ba District (Trinh Dinh Hoang et al. 2015, un-published report). At present, it is almost impossible to persuade local people to reduce their area of Tsao-ko cadarmon fields because this plant brings them the biggest economic income in comparison with any other local plants cultivated.

\section{Priority habitat for conservation of the Quan Ba Tonkin Snub-nosed Monkey population}

Quan Ba District has both evergreen broad-leaved and limestone evergreen broadleaved forests. However, majority of these forests have been seriously degraded, becoming un-suitable habitat for the Tonkin Snub-nosed Monkeys. Moreover, the Cao Ta - Tung forest was designated as watershed protection forest. The forest has been managed by the authorities of Cao Ma Po, Tung Vai and Ta Van Communes. Most of the forest area is allocated to villages for protection and the villagers use this forest for Tsao-ko cardamom farming, non-timber forest products harvesting and wildlife hunting/trapping. According to the Decision No. 186/2006/QD-TTg and the Decision No. 17/2015/QD-TTg of the Prime Minister, cultivation of agricultural and medicinal plant inside of the watershed protection forest is legal. The Quan Ba Forest Protection Department is the government body responsible for protection of the Cao - Ta Tung forest. However, the Department has insufficient number of staff members and lacks a fund to control over-farming of Tsaoko cardamom and conducting other forest protection activities. Consequently, the forests have been destroyed and severely degraded due to intensive Tsao-ko cardamom farming and non-timber forest products harvesting.

This study shows that the best forest habitat for the Quan Ba Tonkin Snub-nosed Monkey population remains only in an area of about 5,000 ha in the Theng Chu Pin, Dao Dai Chai, Ta Lay, Tung Lau mountains, the Hill 754 and the forest patch along the VietnamChina border from the Post 283 to Post 285 (fig. 1). This area must be designated as a special-use forest, i.e. to establish a Quan $\mathrm{Ba}$ Tonkin Snub-nosed Monkey Conservation Area to ensure long-term survival of this special monkey population. This recommendation is fully consistent with the recommendation made in the "Report of Biodiversity Planning of Ha Giang Province until 2020, Vision to 2030", approved by the 
Decision No.1589/QD-UBND, dated 27th August 2015 of the Chairman of Ha Giang Province to establish Quan Ba Conservation Area of about 9,000 ha in the Cao - Ta Tung forest by year 2020 .

\section{Urgent measures to protect the Quan Ba Tonkin Snub-nosed Monkey population}

Along with the establishment of Quan Ba Tonkin Snub-nosed Monkey Conservation Area, the following measures are need to carry out to prevent the Quan Ba Tonkin Snub-nosed Monkey population from further decline. Ha Giang Province and the Conservation organizations should support the Quan Ba Forest Protection Department and the Commune conservation teams to; 1 ) enhance forest patrol and involve local border police to enforce the law in the forest and Tonkin Snub-nosed Monkey protection, 2) conduct more education for local communities on Tonkin Snub-nosed Monkey conservation and forest protection; explain the importance of Tonkin Snub-nosed Monkey conservation and encourage them not to farm Tsao-ko cardamom in the Tonkin Snub-nosed Monkey distribution area, 3) carry out field surveys to get more ecological data on the Tonkin Snubnosed Monkey population and biodiversity values of the proposed Quan Ba Conservation Area to develop more effective conservation measures, 4) enhance collaboration with the neighboring provinces and districts in China for regular information sharing and collaboration in combating trans-border illegal wildlife hunting/snaring and trade, timber logging and other forest disturbances.

\section{CONCLUSION}

Distribution of the Quan Ba Tonkin Snubnosed Monkey population is confined to a small patchy area (about 5,000 ha) belonging to the Theng Chu Phin, Dao Dan Chai and Ta Lay mountains, the Hill 754 and the patches along the Vietnam - China border from the Post 283 to Post 295. This is the best forest in the Cao - Ta - Tung area.

The distribution area of the Quan $\mathrm{Ba}$ Tonkin Snub-nosed Monkey population is covered mostly by forests (92.3\%) and the non-forest land occupies only $7.7 \%$ of the area. There are two types of forest including evergreen broad-leaved forests $(50.0 \%$ of total area) and limestone evergreen broad-leaved forests $(42.4 \%)$. The forests remain only at medium and restoration status. Tsao-ko cardamom Amomum tsao-ko fields are widespread in the evergreen broad-leaved forests. Rich forest of almost primary status remains only in very steep slopes and limestone mountains.

The Cao - Ta - Tung forest has been designated as watershed protection forest allowing farming of agricultural and medicinal plants and the forest farming of Tsao-ko cardamom is widespread in the forests where has become the most serious threat to the Tonkin Snub-nosed Monkey population. The current management status does not support long-term conservation of the Quan Ba Tonkin Snub-nosed Monkey population. In order to ensure long-term survival of the monkey population, the area of the Theng Chu Pin, Dao Dai Chai, Ta Lay and Tung Lau moutains, and the Hill 754 and a forest patches along the Vietnam-China border from the Post 283 to Post 285 must be designated as a special-use forest, i.e. to establish a Quan Ba Tonkin Snub-nosed Monkey Conservation Area.

Acknowledgements: This study was funded by the FFI - Vietnam, US WWF Russell E. Train Education for Nature Program (Agreement No. SX37, 2017) and Ostrava Zoo (Czech Republic). The authors would like to express their sincerely thanks to the Institute of Ecology and Biological Resource, Vietnam Academy of Science and Technology, the Quan Ba District Forest Protection Department and the Authorities of Cao Ma Po, Ta Van and Tung Vai communes for kindly permitting and supporting us to implement this study.

\section{REFERENCES}

Covert H., Le Khac Quyet and B. W. Wright, 2008. On the Brink of Extinction: Research for the Conservation of the Tonkin Snub-nosed Monkey 
Rhinopithecus avunculus. In J. G. Fleagle, C. C. Gilbert (eds.), Elwyn Simons: A Search for Origins. Springer: 409-427.

IUCN, 2019. The IUCN Red List of Threatened Species. Version 2017-3. <www.iucnredlist.org>. Downloaded on 30 April 2019.

Ministry of Agriculture and Rural Development (2009). Circular No. 34/2009/TT-BNNPTN, dated 10th June 2009, on criteria for forest identification and classification (in Vietnamese).

Pham Nhat, 2002. Primates of Vietnam, Agriculture Publisher, Ha Noi, 111 pp. (in Vietnamese).

Prime Minister of Vietnam (2006). Decision No. 186/2006/QD-TTg, dated 14th August 2006 of the Prime Minister on promulgation of Forest Management Regulations.

Prime Minister of Vietnam (2015). Decision No. 17/2015/QD-TTg, dated 9th June 2015 of the Prime Minister on promulgating Management Regulations of Protection Forests.

MOST and VAST, 2007. Red Data Book of Vietnam. Part 1. Animals. Natural Science and Technology Publisher, Ha Noi (in Vietnamese).

Le Khac Quyet, 2004. Distribution and conservation of Tonkin Snub-nosed Monkey Rhinopithecus avunculus in $\mathrm{Du}$ Gia Nature Reserve, Ha Giang Province, Northeast Vietnam. In Nadler T, Streicher U, Ha Thang Long (eds.): Conservation of Primates in Vietnam. Hanoi, Frankfurt Zoological Society, 58-62.

Le Khac Quyet and H. H. Covert, 2010. Another population of the Tonkin Snubnosed Monkey (Rhinopithecus avunculus) discovered in Ha Giang Province, Vietnam. Vietnamese Journal of Primatology 4: 19-25.

Schwitzer C., R. A. Mittermeier, A. B. Rylands, F. Chiozza, E. A. Williamson, J. Wallis and A. Cotton (eds.), 2015. Primates in Peril: The World's 25 Most Endangered Primates 2014-2016. IUCN SSC Primate Specialist Group (PSG), International Primatological Society (IPS), Conservation International (CI), and Bristol Zoological Society, Arlington, VA. iv+93pp. 